\title{
əFuture Changes in the Frequency of Extreme Droughts over China Based on Two Large Ensemble Simulations
}

\author{
Wei Li, ${ }^{a}$ Rongyun Pan, ${ }^{a}$ Zhinong Jiang, ${ }^{a}$ Yang Chen, ${ }^{\text {b,c }}$ Laurent Li, ${ }^{\mathrm{d}}$ Jing-Jia Luo, ${ }^{\mathrm{a}}$ Panmao Zhai, \\ YUCHEN SHEN, ${ }^{\mathrm{e}}$ AND JiNHUA Yu ${ }^{\mathrm{a}}$ \\ ${ }^{\text {a }}$ Key Laboratory of Meteorological Disaster of Ministry of Education, Joint International Research Laboratory of Climate and \\ Environment Change, Collaborative Innovation Center on Forecast and Evaluation of Meteorological Disaster, \\ Nanjing University of Information Science and Technology, Nanjing, China \\ ${ }^{\mathrm{b}}$ State Key Laboratory of Severe Weather, Chinese Academy of Meteorological Sciences, Beijing, China \\ ${ }^{\mathrm{c}}$ Technical Support Unit, Working Group I, IPCC, Université Paris Saclay, Paris, France \\ ${ }^{\mathrm{d}}$ Laboratoire de Météorologie Dynamique, CNRS, Sorbonne Université, Ecole Normale Supérieure, \\ Ecole Polytechnique, Paris, France \\ ${ }^{\mathrm{e}}$ Wuxi Meteorological Observatory of Jiangsu Province, Wuxi, China
}

(Manuscript received 20 August 2020, in final form 15 April 2021)

\begin{abstract}
Future changes in the frequency of extreme drought events are of vital importance for risk assessment and relevant policy making. But a reliable estimation of their probability is intrinsically challenging due to limited available observations or simulations. Here, we use two large ensemble simulations, 50 members from CanESM2 and 40 members from CESM1 under the future RCP8.5 scenario, to elaborate a reliable projection of the 100-yr drought events (once in a century) under different warming levels. It is however necessary to first remove systematic biases for the simulated temperature and precipitation through a bias-correction method based on quantile mapping. Droughts are diagnosed with the standardized precipitation evapotranspiration index (SPEI), which considers both precipitation and potential evapotranspiration (PET, involving temperature). The results show that the frequency of extreme droughts increases with the continued global warming. Some differences between the two ensembles are also observed, especially for high warming levels. The Chinaaveraged probability of 100-yr droughts that occur once in a century in the current climate increase by a factor of 1.52 (1.44) and 1.90 (2.02) under $1.5^{\circ} \mathrm{C}$ and $2^{\circ} \mathrm{C}$ warming levels in CanESM2-LE (CESM1-LE), respectively. A simple statistical scheme shows that the increasing future risk of extreme droughts is mainly due to the increasing effect of PET on the occurrence of extreme drought events, while the effect of precipitation almost keeps constant with global warming.
\end{abstract}

KEYWORDS: Drought; Extreme events; Statistical techniques; Asia

\section{Introduction}

Drought, one of the main natural causes of agricultural, economic, and environmental damages, is expected to be aggravated under global warming (Dai 2011; Sheffield et al. 2012; Zhao and Dai 2015; Sun et al. 2019). Areas around the world suffering severe droughts have more than doubled from 1970 to 2002, and catastrophic events have frequently been reported in many countries (Kallis 2008; Trenberth et al. 2014; Cook et al. 2015; Williams et al. 2020). China, located in the East Asian monsoon area, is one of the regions in the world suffering large economic losses related to frequent droughts. The direct economic loss caused by drought disaster increased at a rate of 4.8 billion yuan per year over the past 12 years for eastern China (2004-15) (Shi et al. 2020).

Studies have shown that frequent extreme drought events have been observed across China in recent decades ( $\mathrm{Li}$ and Ma 2015; Ma et al. 2017). Yu et al. (2014) found that the number of severe and extreme droughts increased across China during the period from

¿ Denotes content that is immediately available upon publication as open access.

Corresponding author: Wei Li, weili@nuist.edu.cn
1951 to 2010, especially for the northwestern and northeastern parts of China. Southwestern China has witnessed frequent extreme droughts in recent years (Lu et al. 2011, 2014; Yang et al. 2015), with record-breaking events in the summer of 2006, from the autumn of 2009 to the spring 2010, and the summer of 2011 (Wang et al. 2014). The long-lasting drought from autumn 2009 to spring 2010 resulted in economic losses of 19 billion yuan (Barriopedro et al. 2012; Zhang et al. 2012). Southern China, a region generally considered as humid, is also experiencing more frequent droughts than ever before (Fischer et al. 2011; Zhang et al. 2017). The evolution of extreme droughts over China in a warming climate has raised widespread concern among local authorities and civilian societies. A reliable projection of the frequency of extreme droughts over China in the future is very important for developing mitigation and adaption strategies for agriculture, water resources, and human health.

Global climate models (GCMs) are the main tool for projecting future climate. However, raw GCMs are generally at coarse spatial resolutions, unable to conduct the projection at regional scale. The statistical downscaling technique is widely used to produce regionally relevant future projection (Chen et al. 2013; Guo et al. 2020). The downscaling procedure generally includes two major steps: 1) An interpolation is first applied to covert climate variables from the GCM's grid to stations with reliable observed data of present-day climate. 2) 
A bias correction is then used to remove the biases in historical and future simulations by establishing relationships between the model and observation for the historical period, and applying them for the future projection.

In the framework of this general approach, a few studies were reported in the literature investigating drought in China. For example, based on phase 5 of the Coupled Model Intercomparison Project (CMIP5), Yao et al. (2020) studied the evolution of droughts for the period 2011-2100 by using the standardized precipitation evapotranspiration index (SPEI). They found that the frequency of dry conditions (with SPEI $<-1$ ) would increase in the future, especially over northwest China. Wang et al. (2014) reported a similar investigation, with a downscaling technique (spatial disaggregation) applied to CMIP5 models, for the assessment of future drought in Southeast China. They found that the future warming will produce more extreme drought events quantified by SPEI (SPEI < -2) due to the rapid increase of PET, which exceeds the precipitation increasing with global warming progresses.

It is worthy of note that the drought frequency defined and used in these studies was based mainly on a fixed threshold of the drought index, which allowed accounting for the number of severe or extreme droughts. The same methodology was also found in Leng et al. (2015) and Miao et al. (2020). Despite its efficacy and simplicity, this intuitive methodology is inaccurate for rare events with small probabilities. Much more effort needs to be made within the probabilistic perspective. And this constitutes the primary motivation for our present study, targeting changes in drought events that occur once every 100 years in the current climate. Although the occurrence probability of such events is low, they could seriously impact the ecological environment and economic and social development. We should immediately recognize that, due to the limitation of adequate samples, it is difficult to accurately estimate the probability of extreme droughts.

There are two methodological approaches to assess extreme events, either with a direct sampling method if there are sufficient samples or using a statistical model (e.g., generalized extreme values) when extreme records are short (Kharin et al. 2013; Li et al. 2018). The latter needs to assume that extreme events follow a given probability distribution. The probability of unobserved extreme events can be estimated by extrapolating sample statistics of limited records. Large "initial-condition" ensemble experiments have been developed in recent years (Jeffrey et al. 2013; Kay et al. 2015; Rodgers et al. 2015; Maher et al. 2019), providing an opportunity to use sampling to estimate probability of extremes. Ensemble members from each experiment are subjected to the same external forcing but are started from different initial conditions. Multiple realizations from one model can provide a satisfactory sampling of extreme events, which can allow us to study the extreme events with return period of more than 100 years by means of sampling, without the requirement of fitting to any probability distribution (Sippel et al. 2015; Lehner et al. 2016; Tanaka et al. 2018; Deser et al. 2020). Van der Wiel et al. (2019) compared those two methodologies and reported that the large ensemble approach can improve the estimation of extreme events with long return period, and reduce the uncertainties in the risk of such extreme events in their risk projection in the future.

The focus of this paper is on the changes in the frequency of extreme droughts under different global warming levels over China by using two large ensemble simulations from the Canadian Centre for Climate Modeling and Analysis (CCCma) secondgeneration Canadian Earth System Model (CanESM2-LE) and the National Center of Atmospheric Research (NCAR) Community Earth System Model version 1 (CESM1-LE). Zhao et al. (2020) also used those two large ensembles to investigate meteorological and hydrological droughts in North America. Our work, focusing on China, complements Zhao et al. (2020) and can provide useful information for the development of adaptation strategies to the increasing occurrence of drought hazards in China. For this purpose, we need to understand how extreme droughts change under different warming levels and for the whole territory of China. Furthermore, with a simple statistical scheme, our work will also help to assess possible influences of PET and precipitation on the future risk of extreme droughts. Our research is expected to provide useful information for the local stakeholders and policymakers.

The structure of this paper is as follows: section 2 and section 3 introduce the data and methods, respectively. The projected frequency of extreme drought event is presented in section 4 , followed by a discussion in section 5. Finally, section 6 summarizes the conclusions.

\section{Data}

\section{a. Observation dataset}

We used daily precipitation and temperature data collected by the China Meteorological Administration from 726 meteorological stations covering the period from 1961 to 2017 (available online at http:/data.cma.cn/data/cdcdetail/dataCode/ A.0029.0001.html). Rigorous quality control procedures have been applied to this dataset by the National Meteorological information center (Qian and Lin 2005). We finally selected 603 stations with no missing values in the record for any year during this period. These 603 stations are shown in Fig. 1.

The characteristics of climate over China vary significantly from region to region due to China's large geographic extent and complex terrain. To better understand future changes in extreme droughts in different regions, it is helpful to divide the whole Chinese territory into subregions. We used six subregions (Fig. 1): northwest China (NW: $\left.35^{\circ}-50^{\circ} \mathrm{N}, 74^{\circ}-105^{\circ} \mathrm{E}\right)$, southwest China (SW: $20^{\circ}-35^{\circ} \mathrm{N}, 90^{\circ}-105^{\circ} \mathrm{E}$ ), northeast China (NE: $42^{\circ}-$ $55^{\circ} \mathrm{N}, 105^{\circ}-134^{\circ} \mathrm{E}$ ), north China (NC: $35^{\circ}-42^{\circ} \mathrm{N}, 105^{\circ}-125^{\circ} \mathrm{E}$ ), the Yangtze River valley (YZ: $28^{\circ}-35^{\circ} \mathrm{N}, 105^{\circ}-123^{\circ} \mathrm{E}$ ), and southeast China (SE: $\left.18^{\circ}-28^{\circ} \mathrm{N}, 105^{\circ}-120^{\circ} \mathrm{E}\right)$. In this way, different subregions show different climate characteristics. This definition of subregions has also been widely used in previous studies (Ma et al. 2015; Qiu et al. 2017).

\section{b. Model dataset}

We used two large initial-condition ensembles to try to robustly assess the change in the frequency of extreme droughts 


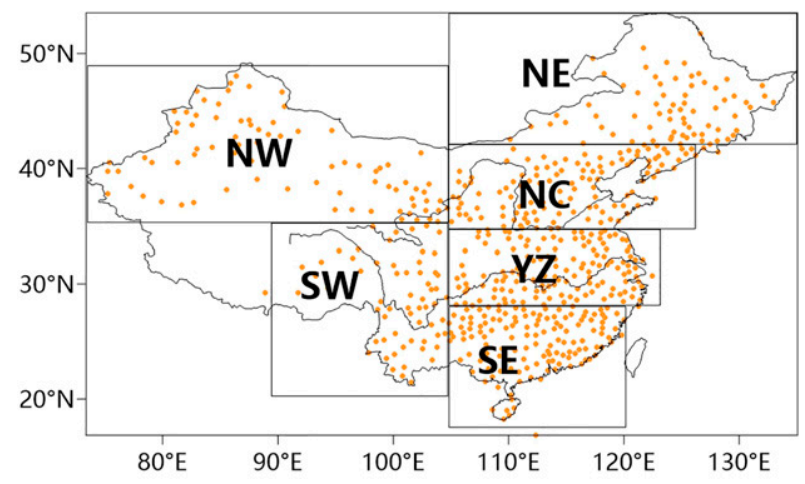

FIG. 1. Location of 603 stations used in this study and the six subregions of China: northwest China (NW: $\left.35^{\circ}-50^{\circ} \mathrm{N}, 74^{\circ}-105^{\circ} \mathrm{E}\right)$, southwest China $\left(\mathrm{SW}: 20^{\circ}-35^{\circ} \mathrm{N}, 90^{\circ}-105^{\circ} \mathrm{E}\right)$, northeast China (NE: $\left.42^{\circ}-55^{\circ} \mathrm{N}, 105^{\circ}-134^{\circ} \mathrm{E}\right)$, north China (NC: $35^{\circ}-42^{\circ} \mathrm{N}, 105^{\circ}-125^{\circ} \mathrm{E}$ ), the Yangtze River valley (YZ: $28^{\circ}-35^{\circ} \mathrm{N}, 105^{\circ}-123^{\circ} \mathrm{E}$ ), and southeast China (SE: $18^{\circ}-28^{\circ} \mathrm{N}, 105^{\circ}-120^{\circ} \mathrm{E}$ ). The small inset in the bottom right represents the South China Sea.

over China under different warming levels. The first one was conducted with the CanESM2 at a spatial resolution of $2.8^{\circ} \times$ $2.8^{\circ}$, referred to hereafter as the CanESM2 large ensemble (CanESM2-LE), CanESM2-LE consists of 50 members for the period 1950-2100, each subject to identical external radiative forcing but beginning from slightly different atmospheric initial conditions (Arora et al. 2011; Kirchmeier-Young et al. 2017). Following the CMIP5 design protocol, observed natural and anthropogenic forcing was applied for the historical period from 1950 to 2005 and representative concentration pathway 8.5 (RCP8.5) radiative forcing was used for 2006-2100. Five simulations covering the 1850-1950 historical period were performed to generate five different states of the ocean in 1950. Then, 10 coupled ocean-atmospheric simulations were run from each of these five historical simulations using randomly perturbed initial conditions (in 1950), for a total of fifty $150-\mathrm{yr}$ simulations over the 1950-2100 period.

The second large initial-condition ensemble is made up of 40 simulations, derived from CESM1 (CESM1-LE; Kay et al. 2015). CESM1-LE has a horizontal resolution of approximately $1^{\circ}$ in latitude and longitude. The model ensemble members were generated by beginning from a slightly perturbed initial temperature field within the range of round-off errors for each realization. As in CanESM2-LE, the CMIP5 historical forcing was applied before 2005 and RCP8.5 radiative forcing was applied from 2006 until the end of twenty-first century in CESM1-LE. More description of CESM1-LE is given in Kay et al. (2015). Daily precipitation and temperature from 1961 to 2100 were used in both ensembles.

\section{Method}

\section{a. Drought index}

A few drought indices can be used to characterize and quantify droughts and their properties. These include the Palmer drought severity index (PDSI), standardized precipitation index
TABLE 1. The 21-yr period when global mean surface temperature reaches to $1.0^{\circ}, 1.5^{\circ}, 2.0^{\circ}, 3.0^{\circ}$, and $4.0^{\circ} \mathrm{C}$ relative to preindustrial period for CanESM2-LE and CESM1-LE.

\begin{tabular}{lccccc}
\hline \hline \multicolumn{1}{c}{ Model } & $1.0^{\circ} \mathrm{C}$ & $1.5^{\circ} \mathrm{C}$ & $2.0^{\circ} \mathrm{C}$ & $3.0^{\circ} \mathrm{C}$ & $4.0^{\circ} \mathrm{C}$ \\
\hline CanESM2-LE & $1990-2010$ & $2004-24$ & $2017-37$ & $2038-58$ & $2056-76$ \\
CESM1-LE & $2006-26$ & $2020-40$ & $2032-52$ & $2051-71$ & $2070-90$ \\
\hline
\end{tabular}

(SPI), and SPEI. Different indices have their own advantages and limitations in drought monitoring. Among them, SPEI is widely used, due to its multiscale nature and ability to identify different types of drought (Vicente-Serrano et al. 2010). SPEI quantifies the extent of atmospheric water surplus or deficit relative to long-term average conditions by standardizing the difference between precipitation and potential evapotranspiration (PET).

In this study, we used Thornthwaite's method to calculate PET. We know that the Penman-Monteith approach is thought to give a more realistic estimation of PET. However, it requires additional variables including solar radiation, relative humidity, wind speed, and sunshine duration. Although model outputs include these fields, there are no adequate observational data of these variables for their bias correction. Thus, we choose the Thornthwaite method to calculate PET, which has the advantage of requiring only the monthly temperature (Thornthwaite 1948). The difference between these two methods over China was reported by many researchers, who pointed out that a slight difference was found in humid regions while the difference in arid regions was quite large (Li et al. 2014, 2017; Chen and Sun 2015). In this study, SPEI at a time scale of 12 months was used to represent the drought, because 12-month SPEI can well represent the precipitation deficit for the entire year.

\section{b. Global warming levels}

In this paper, the occurrence probability of extreme droughts (100-yr events in the current climate) is projected under the specific global warming levels, including $1^{\circ}, 1.5^{\circ}, 2^{\circ}, 3^{\circ}$, and $4^{\circ} \mathrm{C}$ above the preindustrial level. CanESM2 produced, with observed historical forcing, a five-member ensemble for 1850-2005 in the framework of CMIP5, which allows us to estimate the global mean surface temperature (GMST) during the preindustrial period (1860-1900). The GMST in the preindustrial period in CESM1-LE was directly calculated in its first run. The time series of GMST anomalies relative to preindustrial was first smoothed with a 9-yr moving average. The first year when the smoothed GMST curve crosses the specific warming level was then considered as the center for the target warming window (21 years), with two 10-yr periods around. This time slice selection method is widely used to estimate the future climate under fixed warming threshold (Sun et al. 2018; Shi et al. 2018). The 21-yr periods corresponding to these warming levels are listed in Table 1 . The $1.0^{\circ} \mathrm{C}$ warming level is used to represent the current climate, which has actually warmed up about $+1^{\circ} \mathrm{C}$ compared with the preindustrial period based on observations (World Meteorological Organization 2019). As noticed previously, CanESM2 has a higher transient climate response (TCR) 
than CESM1; that is, the time when GMST reaches a fixed warming threshold is earlier in CanESM2 than in CESM1.

\section{c. Bias correction}

The output of climate models does not usually reproduce the statistical properties of observations at stations in the current climate due to limited spatial resolution, simplified physics, and incomplete knowledge of the climate system. Failing to correct these biases may result in unrealistic historical simulation and future projection. Many researchers have pointed out that GCMs underestimate the precipitation in humid regions (south China) but overestimate it in arid regions (western China) (Jiang et al. 2015; Ou et al. 2013). Meanwhile, cold biases have also been found in many GCMs. This paper used a bias-correction method based on quantile mapping to reduce model errors (Chen et al. 2013, 2019). To deal with the issue of spatial scale difference between model output and station observation, we used an inverse distance-weighted interpolation method to convert or downscale daily precipitation and temperature from model grid to the observed network of 603 stations across China.

The interpolation was followed by the bias correction of the model output to match with observed data for each station. The bias correction that we used involves distribution-based quantile mapping technique. It is worthy of note that, for daily precipitation, the local intensity scaling was first applied to ensure that the number of wet days $\left(>0.1 \mathrm{~mm}\right.$ day $\left.^{-1}\right)$ simulated by a model is consistent with what observation. The gamma function was used for the daily precipitation probability distribution, which constitutes a good approximation for the probability distribution of both observed and simulated precipitation. The bias-corrected data of future projection were generated by replacing the model precipitation by its value resampled from the gamma distribution fitted to the observations and associated with the same quantile. This method was found to perform well when used on GCMs outputs over China, especially for extremes (Yang et al. 2018; Yao et al. 2018). As for temperature, the bias correction follows the same approach as for precipitation, but an empirical distribution was used to match the observed distribution through a transfer function.

The correction was calibrated in the observed reference period (1985-2005) and the period in model when the simulated warming is closest to the observed warming (1992-2012 for CESM1-LE and 1978-98 for CanESM2-LE). The correction was applied 1) to the current climate $\left(1^{\circ} \mathrm{C}\right.$ warming, relative to preindustrial $)$ to evaluate the performance of bias correction with its observed 21-yr period (1998-2018), and 2) to future warming climate to produce a bias-corrected climate projection.

\section{d. Return period of extreme drought index}

CanESM2-LE and CESM1-LE provide a sampling of 1050 $(50 \times 21)$ and $840(40 \times 21)$ model years, respectively. And this for each of our period of investigation. Such a large sampling allows us to directly compute drought events with large return periods (up to 100 years) using an empirical distribution. In this work, an unbiased estimation formula was used to calculate the future return period $T$ for an extreme drought event in the current climate. This method has been commonly used in climatology research (Cunnane 1978; Folland and Anderson 2002; Zhang and Singh 2006; Zhao et al. 2020):

$$
T=\frac{N+0.2}{m-0.4}
$$

where $N$ represents the number of extreme samples ( 840 for CanESM2-LE and 1050 for CESM1-LE) used. The series of $N$ values being ranked in ascending order, the rank of an event corresponding to a specific chosen return period (e.g., 100-yr event) is the following:

$$
m=(N+0.2) / 100+0.4 \text {. }
$$

The future return period of the event with rank $m$ in current climate can be estimated with Eq. (1). This estimation can ensure that the estimated return period is an optimal unbiased one for the underlying gamma distribution.

In practice, the smallest annual SPEI values for each model year were first calculated from monthly SPEI to constitute our samples of extreme droughts. We can then estimate the SPEI value with 100 -yr return period by applying Eq. (2) in current climate, and to deduce the return period of this SPEI value under different warming levels by using Eq. (1).

A 100-yr drought represents a drought event that occurs on average once every 100 years. In other words, it has a probability of occurrence of 1/100 for each year. The return period of a current 100 -yr drought in future climate reflects the change in drought frequency. The event will become more frequent if the future return period is shorter and less frequent if the future return period is longer. We also use the risk ratio (or probability ratio, denoted as $\mathrm{PR}$ ) defined by $\mathrm{PR}=P_{1} / P_{0}$ to assess risk changes at regional level: $P_{1}$ represents the future probability of a current $100-\mathrm{yr}$ drought event, and $P_{0}$ represents its current probability (e.g., $1 / 100=0.01$ ).

\section{Results}

\section{a. Performance of the ensemble simulations}

The raw and bias-corrected annual total precipitation is first evaluated in current climate in the two ensembles. As shown in Fig. 2, the two ensembles generally overestimate the annual total precipitation over northern China with maximum biases (over $200 \%$ ) over north-central China. But the two ensembles underestimate annual total precipitation over southeastern China with maximum negative biases reaching nearly $60 \%$. The bias correction can reduce the bias remarkably, to a level smaller than $10 \%$ over southern China and $20 \%$ over north China. In addition, it is of utmost importance to examine the model performance in simulating the seasonal variation of precipitation. Generally, those two bias-corrected ensembles can well reproduce the annual cycle of precipitation, especially for CESM1-LE due to its higher spatial resolution (figure not shown).

Figure 3 displays the raw and bias-corrected annual cycle of temperature averaged across China in the two ensembles, together with the observed counterpart. The raw ensemble underestimates temperature year-round, especially in winter. For example, CanESM2-LE underestimates the observed January temperature by $1^{\circ} \mathrm{C}$ and CESM1-LE by $3^{\circ} \mathrm{C}$. The bias-corrected temperature shows a good agreement with observation with cold biases significantly reduced.

Overall, the bias-corrected ensembles can both well reproduce the characteristics of observed precipitation and 

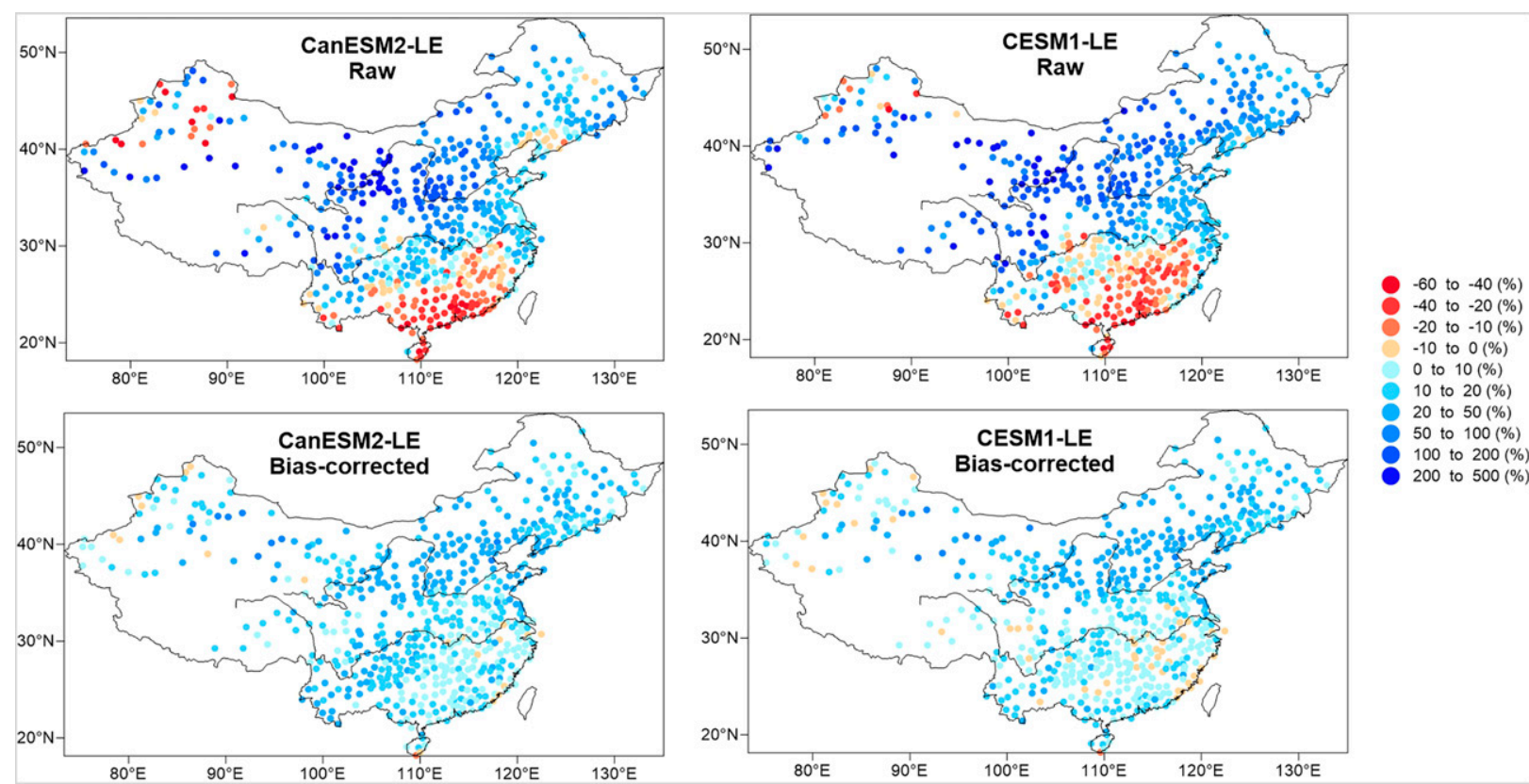

FIG. 2. Spatial pattern of bias for climatology of total annual precipitation during the current climate in the raw ensemble and biascorrected ensemble relative to observation for (left) CanESM2-LE and (right) CESM1-LE.

temperature, which gives us some confidence for their future projection.

\section{b. Changes in the frequency of extreme droughts under different warming levels}

We mostly focus on changes of the current 100-yr droughts in different future warming climates (Fig. 4), because changes for an event of long return period always led to large socioeconomic losses. The distribution of drought events with other long return periods is similar to that of the 100 -yr event, with just some differences in magnitude (figure not shown). The frequency of 100-yr extreme droughts in both ensembles increases with global warming. However, the pattern shows differences between them, especially for low warming levels. In CanEMS2-LE, parts of central and eastern China show a decrease in probability of 100-yr events. In CESM1-LE, the regions with a decrease are located in southeast China, southwest China, and southern China. The pattern becomes more consistent between the two ensembles under higher warming levels, with the largest increase over northwestern China and a decrease over parts of southwestern China.

Precipitation and temperature are the two main factors contributing to the development of extreme droughts, the former
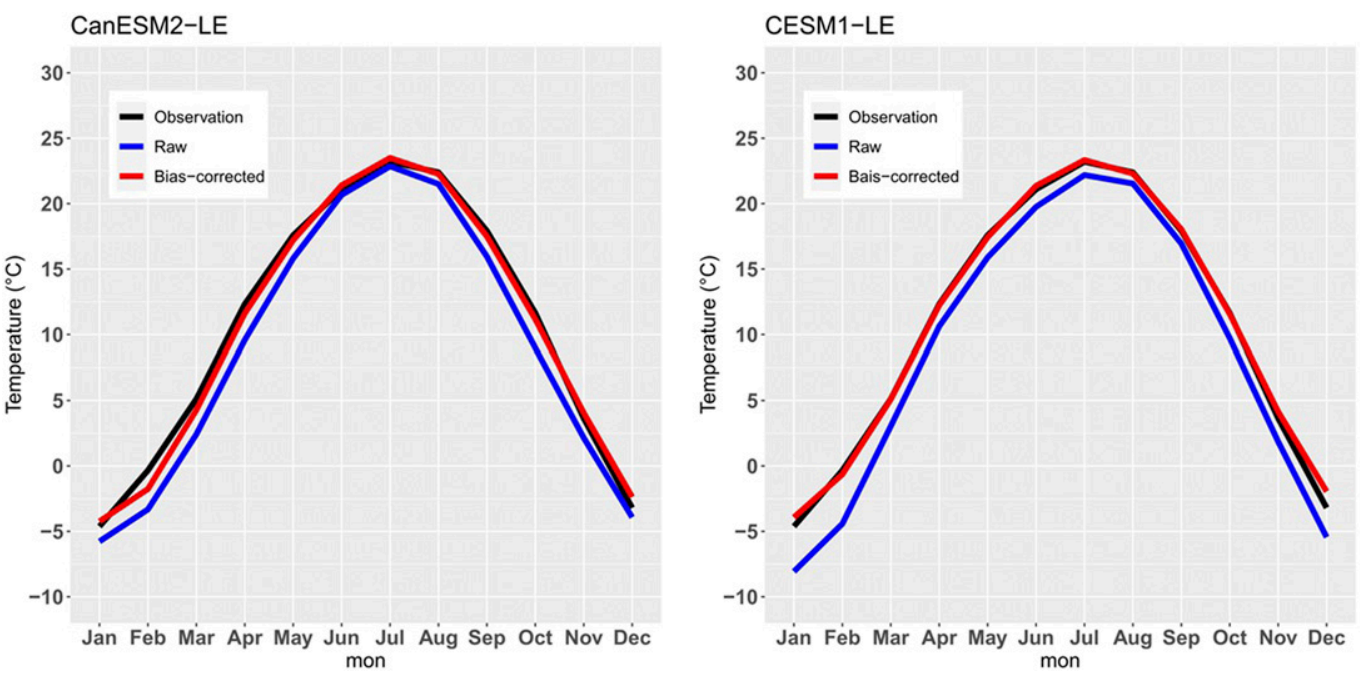

FIG. 3. Observed (black), raw (blue), and bias-corrected (red) annual cycles of temperature averaged across China for (left) CanESM2-LE and (right) CESM1-LE. 


\section{CanESM2-LE}
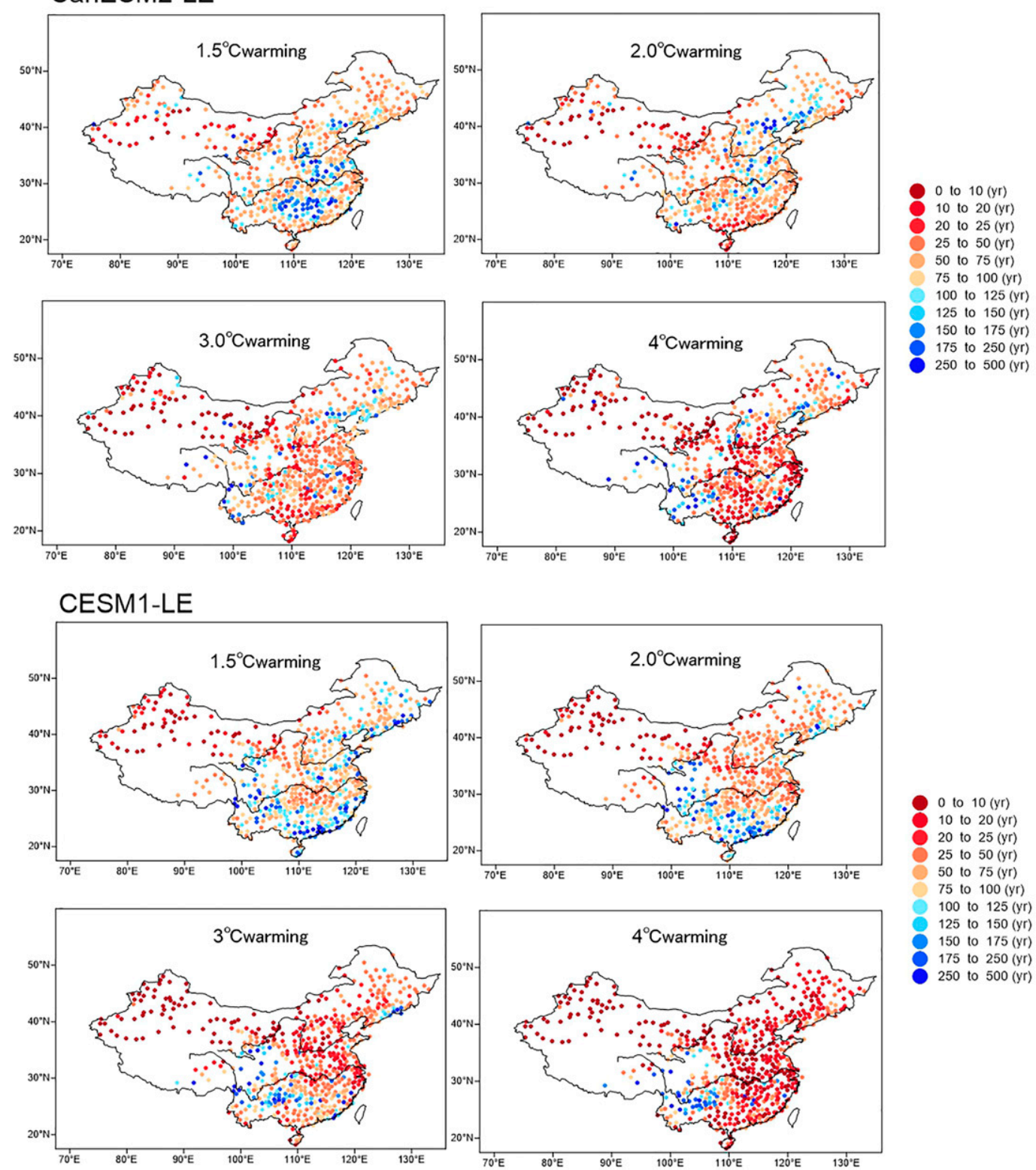

250 to $500(\mathrm{yr})$

FIG. 4. The return period of 100-yr drought events in the current climate under different warming levels in CanESM2-LE and CESM1-LE.

mainly through the influence on evapotranspiration, and the latter by directly changing the available water on the surface. To investigate the relevant mechanism underlying the changes of extreme droughts, it is essential to study the contribution of precipitation and temperature to the occurrence of extreme droughts. The future changes in annual total precipitation (relative change) and annual mean temperature (absolute change) relative to current climate under different warming levels are displayed in Figs. 5 and 6, respectively.

A notable feature in Fig. 5 is that the precipitation exhibits a uniform increase across China with the most notable increase in northwestern China. The patterns exhibit little difference between the two ensembles in eastern China. A larger increase in northern China than in southern China can be found in CanESM2-LE. Taking the $3^{\circ} \mathrm{C}$ warming climate as an example, the precipitation increase exceeds $15 \%$ in northern China, whereas the increase is no more than $10 \%$ in southern China. But a larger increase in southern China than in northern China can be found in CESM1-LE.

Changes in temperature, another important variable determining drought, are highlighted in Fig. 6. A homogenous warming pattern can be seen across the whole region, with greater warming in western and northeastern China, and weaker warming in southeastern China. This spatial structure is generally stable 

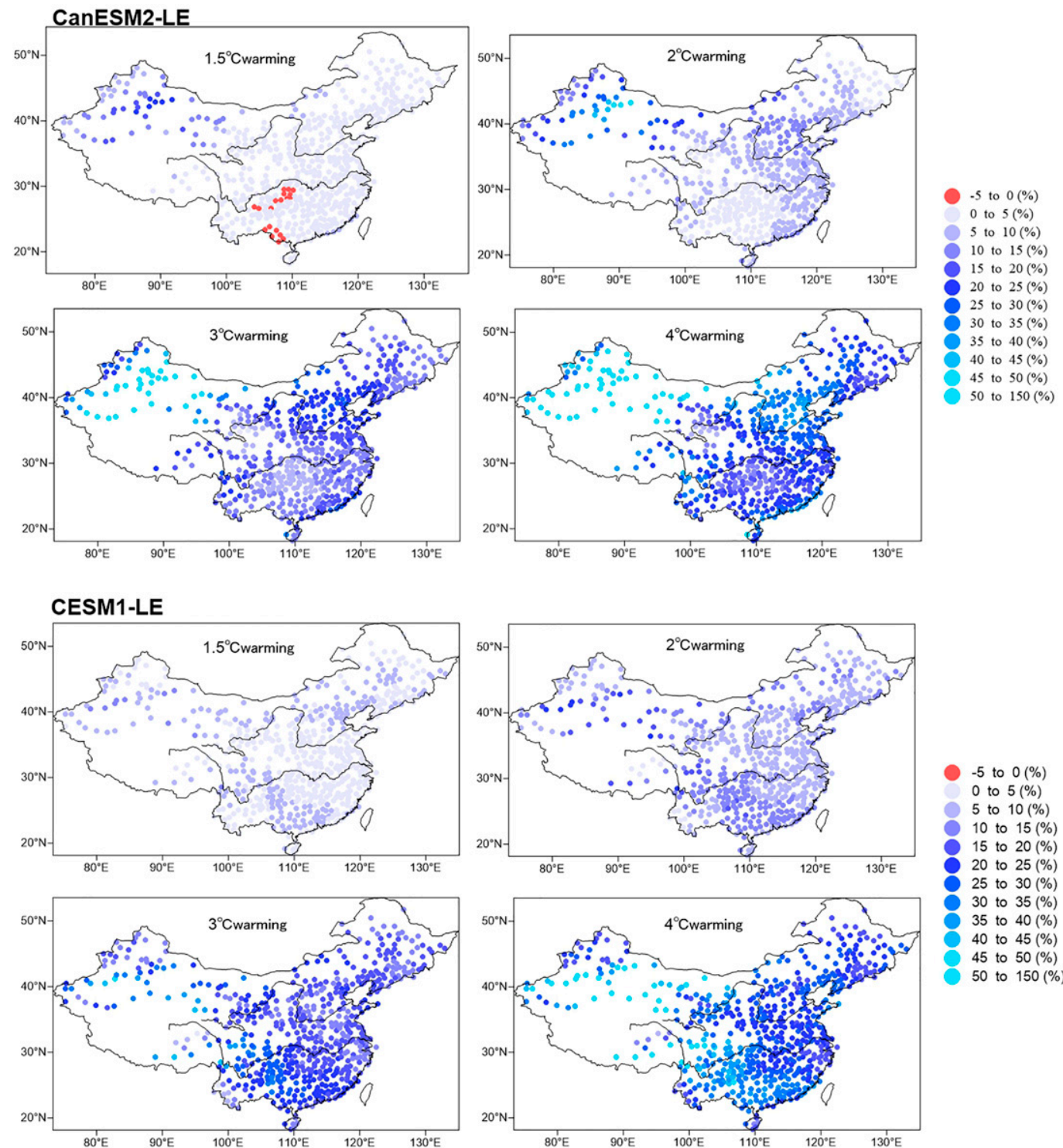

FIG. 5. Projected changes in annual total precipitation under different warming levels relative to the current climate for CanESM2-LE and CESM1-LE.

among the different warming climates. However, the magnitude of warming increases with a rise in global mean temperature for both ensembles. For example, when the global temperature warms by $1.5^{\circ} \mathrm{C}$, the increase in mean temperature exceeds $0.5^{\circ} \mathrm{C}$ relative to the current climate over most of China, and exceeds $1^{\circ} \mathrm{C}$ over northwestern China. When global warming reaches $4^{\circ} \mathrm{C}$, the temperature exceeds $3^{\circ} \mathrm{C}$ over most parts of the region, and northwestern China experiences a warming of more than $4^{\circ} \mathrm{C}$. The pattern of temperature changes shows no direct link with changes in the frequency of extreme droughts.

The changes in precipitation and temperature share a similar pattern with the largest increases appearing in northwestern China. More precipitation could bring fewer droughts, but warmer temperature could enhance evaporation from the soil, producing more droughts. The effect of temperature changes on extreme droughts is somewhat counteracted by the projected increase in precipitation. Thus, future changes in drought frequency can have complex behaviors because of the competition effect between changes in precipitation and temperature.

We used risk ratio to quantify the changes in probability of current extreme 100-yr events under different warming levels. Figure 7 shows the area-weighted averaged risk ratio for whole China and its subregions. The area-weighted averaging has been a widely used approach in climate change research (Zhai et al. 2005; Sun et al. 2014; Yin and Sun 2018). We first divide all of China into boxes of $2.5^{\circ} \times 2.5^{\circ}$ in latitude and longitude and then calculate each box value as the mean of all available station data in the box. The box value is set as missing when no 

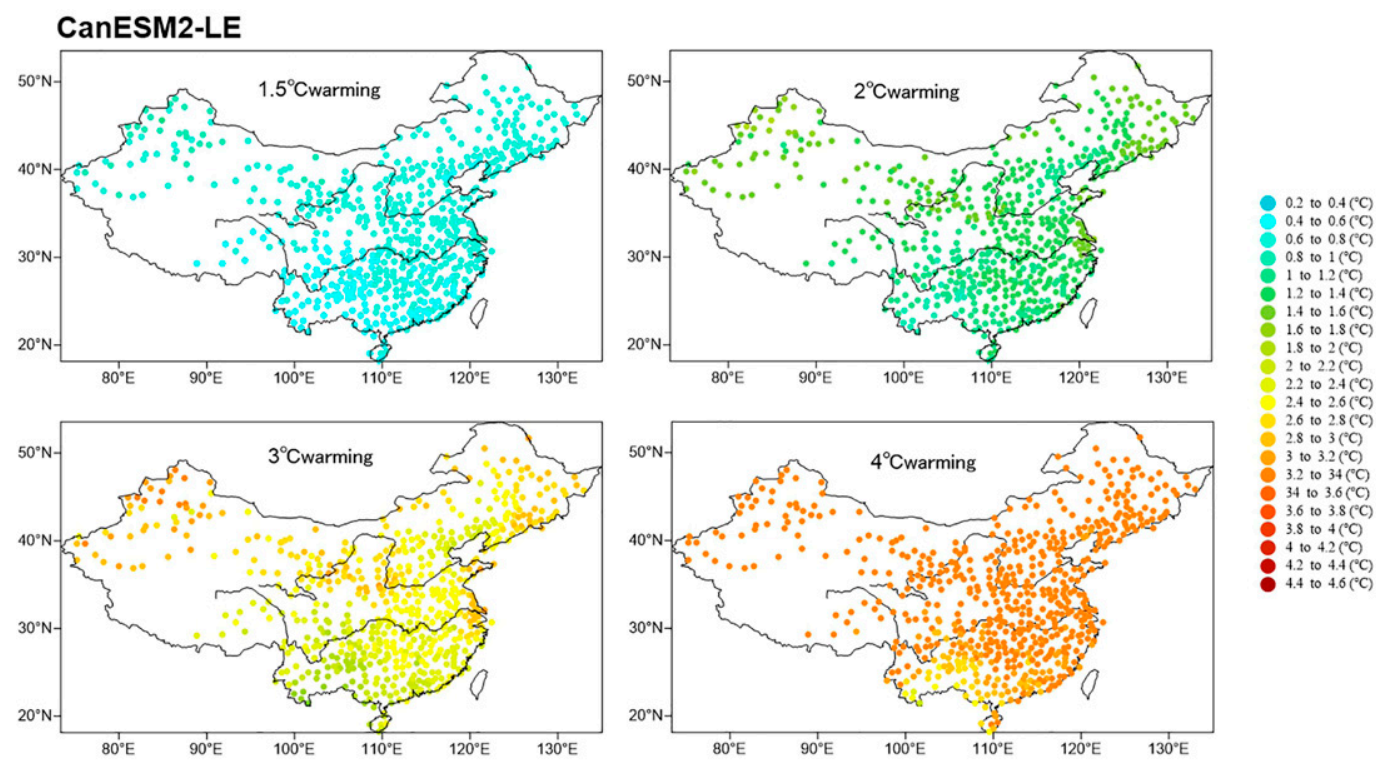

4 to $2.6(\mathrm{CC})$

2.6 to $2.8 \mathrm{C}^{\circ} \mathrm{C}$

2.8 to $3(\mathrm{C})$
3 to $3.2(\mathrm{C})$
3.2 to $\left.34 \mathrm{C}^{\circ} \mathrm{C}\right)$

34 to $3.6\left(^{\circ} \mathrm{C}\right)$
3.6 to $3.8\left(^{\circ} \mathrm{C}\right)$

3.8 to $4(\mathrm{CC})$

4.2 to 4.4 (c)

CESM1-LE
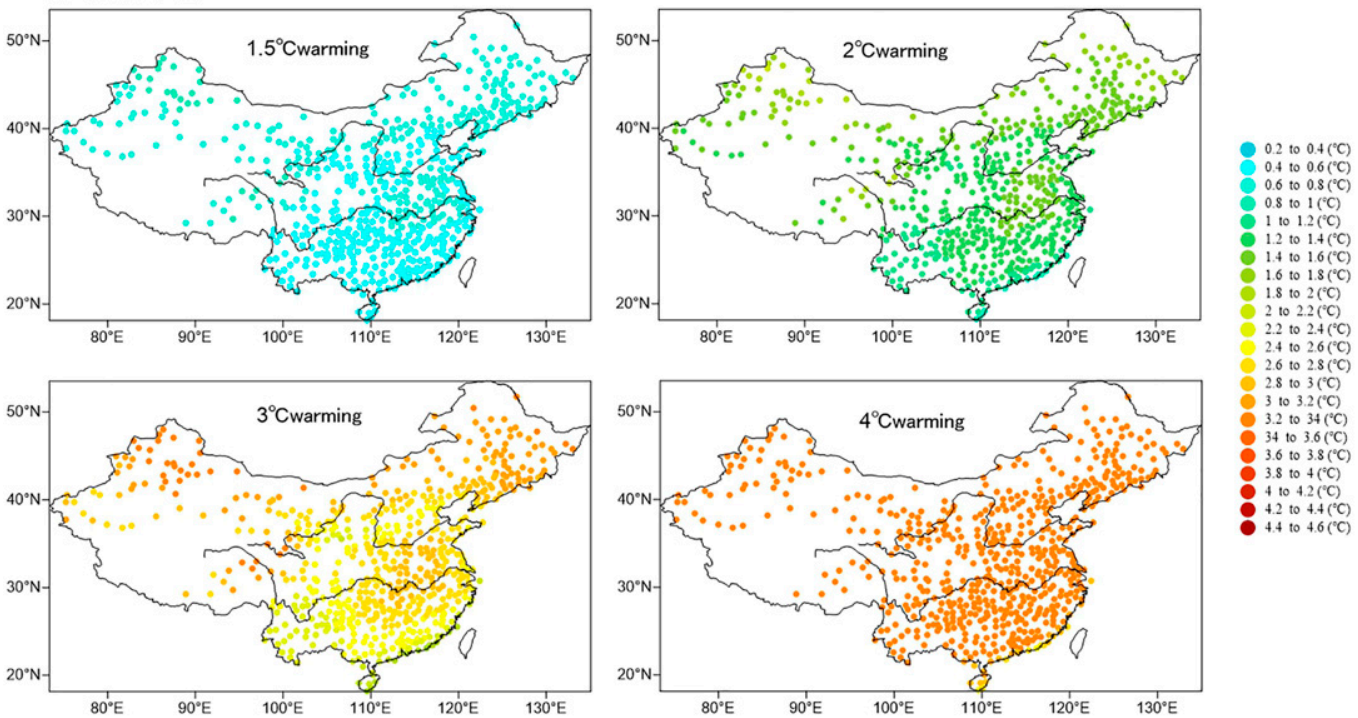

FIG. 6. As in Fig. 5, but for temperature.

stations fall into the box. Finally, the regional average was obtained as the general mean of all boxes in the region with area as weight. Note that SPEI based on the Thornthwaite equation may produce large errors when it is used to monitor drought conditions over northwestern China. This is partly due to the amplified effect of temperature enhancement in the arid region, intrinsically related to the Thornthwaite approach, which has been widely reported in previous research (Chen and Sun 2015). Thus, we exclude the NW subregion from our regional analysis.

In general, the probability of extreme droughts is projected to increase in response to global warming. The magnitude of risk ratio in CESM1-LE is larger than that in CanESM2-LE, especially under higher warming levels. The average probability across China for the 100-yr event increases by a factor of 1.52 (1.44), 1.90 (2.02), 2.82 (3.83), and 4.43 (7.93) under the four warming levels in CanESM2-LE (CESM1-LE), respectively. Generally, the risks ratio in all subregions increase with global warming, especially for higher warming levels. The future changes in probability show large distinctions among subregions and exhibit a notable difference between the two large ensembles. Two subregions located in south China, SE and YZ, exhibit larger increase in risk ratio than other subregions for CanESM2-LE, while NC and NE in north China show larger increase for CESM1-LE. For SW, a weak increase in occurrence of extreme drought event can be seen in CESM1-LE, whereas a slight decrease in the risk ratio can be found for CanESM2-LE. 

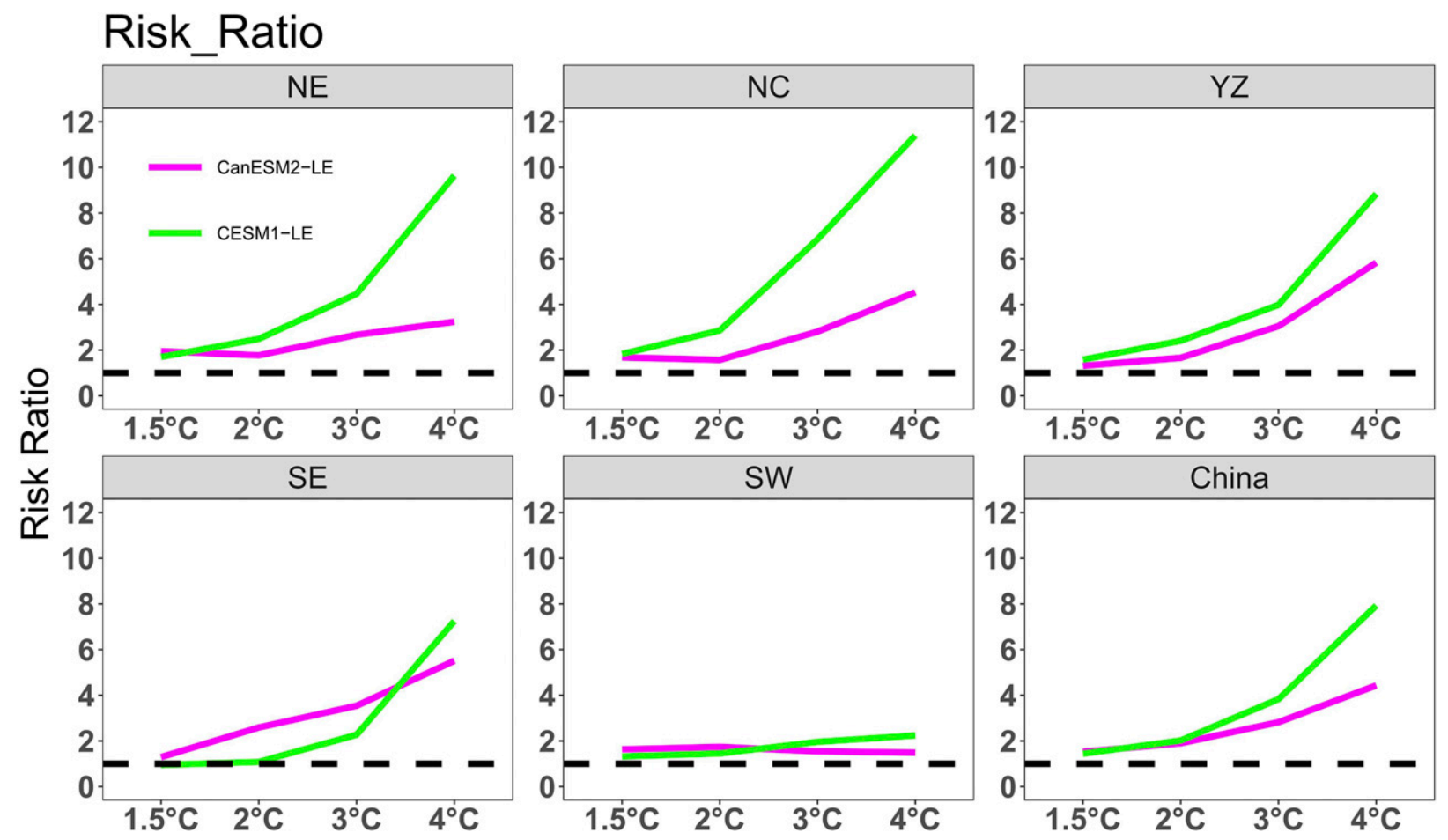

FIG. 7. Spatially averaged of future changes in 100 -yr extreme droughts in the current climate under $1.5^{\circ}, 2^{\circ}, 3^{\circ}$, and $4^{\circ} \mathrm{C}$ for CanESM2LE (magenta) and CESM1-LE (green) for the whole of China and its subregions (NE, NC, YZ, SE, SW). The dashed horizontal line represents a $\mathrm{PR}$ equal to one.

To illuminate possible reasons explaining the future changes of extreme droughts, we now examine the influence of precipitation and PET, two key ingredients, in the future risk of extreme droughts. We designed two additional experiments. In the first one, the drought index, noted hereafter as $\mathrm{SPEI}_{1}$ is calculated by holding PET at its mean annual cycle in the current climate and only allowing precipitation to vary. The future probability of a given SPEI value in this situation would be smaller compared to the normal situation (both PET and precipitation changing with time), since the effect of increasing PET in drier conditions is suppressed in $\mathrm{SPEI}_{1}$. We can use fraction of probability due to PET (PEF), defined as $\left(P-P_{1}\right) / P \times 100 \%$, to quantify the influence of changing PET on the future risk of extreme droughts, where $P$ is the future probability of the current 100 -yr drought.

In the second experiment, $\mathrm{SPEI}_{2}, \mathrm{PET}$ varies but precipitation is held at its mean annual cycle value in current climate. The opposite effect is expected, since increasing precipitation would alleviate droughts. The future probability of a given SPEI value, derived from $\mathrm{SPEI}_{2}$, would be larger compared to the normal situation. It is useful to define the fraction of probability to precipitation $(\mathrm{PF})$ as $\left(P_{2}-P\right) / P_{2} \times 100 \%$ to quantify the influence of precipitation changes on the future risk of extreme droughts. PEF and PF were calculated for each station and area-weight averaged over China and over the six subregions. We used them to assess future risk of extreme droughts. Results are displayed in Fig. 8.

In general, PEF shows a higher increase magnitude than PE does, with GMST significantly rising across China. That is to say, the importance of PET as a contributor to the future risk of extreme droughts will increase in the future, which is the main reason why the two ensembles (from two different models) produce both more frequent extreme droughts under warming climate. The importance of precipitation, a factor of alleviation of future risk of extreme droughts, seems to keep constant in the future. Over the SW region, the importance of PEF and PE both show increase trend with warming in the two models with larger increase in PEF and smaller increase in PF across all warming levels, which makes SW to become the weakest changes in probability of extreme drought among all subregions. This condition also happens over NE in CanESM2-LE.

\section{Discussion}

The results that we presented in this paper are based on two large ensemble simulations, which allows us to accurately estimate the occurrence probability of extreme droughts by providing enough statistical samples. We also applied a simple quantile-mapping bias correction to model outputs, and we succeed in obtaining a good performance in simulating both precipitation and temperature in China. We are thus more confident in our future projection of extreme drought events. Remarkable differences, however, do exist between the two ensembles, with a larger increase in CESM1-LE than in CanESM2-LE. Southwestern China even shows opposite sign of changes. At this stage of our investigation, we presume that results from CESM1-LE are more reliable since it has a higher 

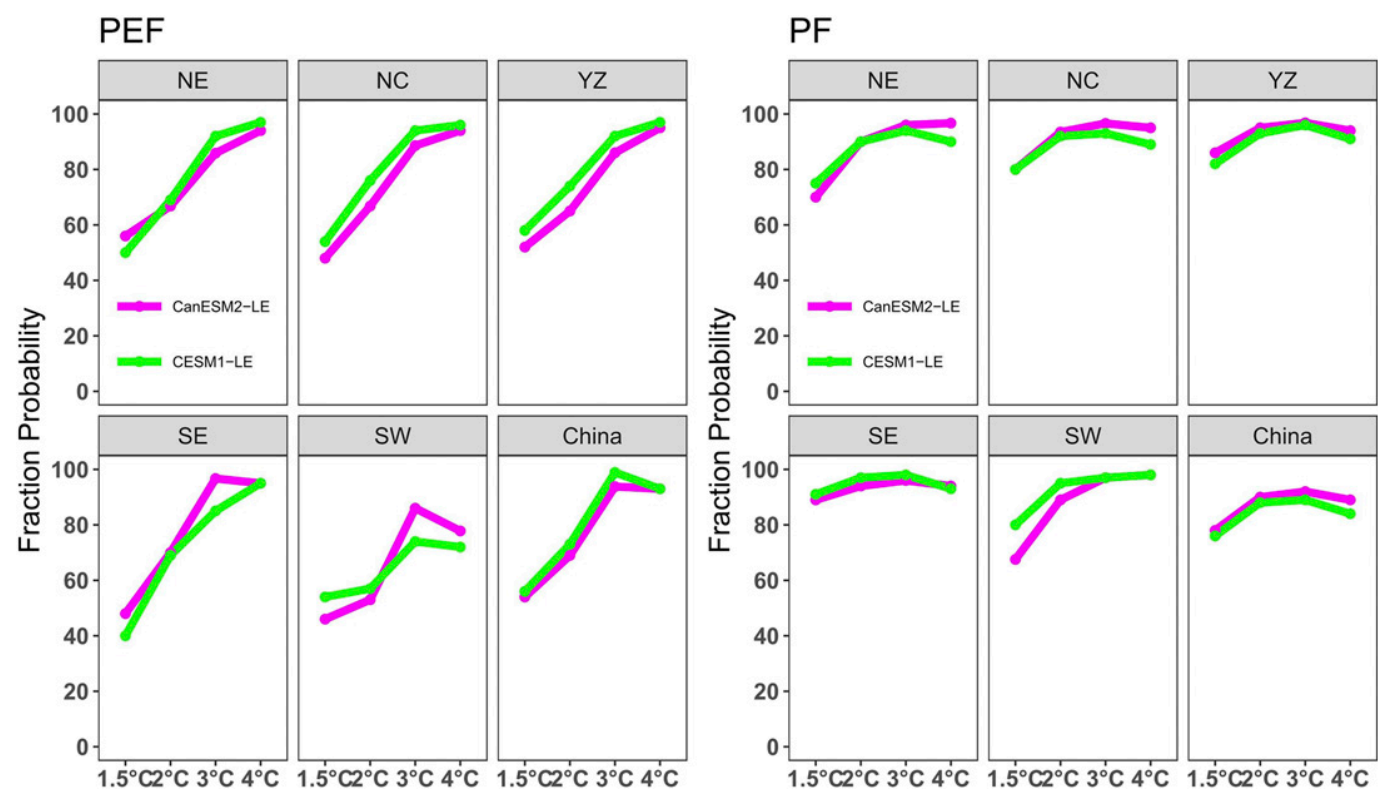

FIG. 8. The area-weighted averaged of PEF and PF over China and its subregions (NE, NC, YZ, SE, SW) under different warming levels for CanESM2-LE (magenta) and CESM1-LE (green).

spatial resolution and a better performance in reproducing extreme droughts in its current climate.

Despite the requirement of computational resources in performing large ensemble simulations, a few modeling groups are beginning to release data of their large-ensemble simulations. This will allow us to explore results from multiple models and reduce uncertainties arising from different climate models. GCMs exhibit quite a large diversity in changes of drought events at the subregional scale. Thus, more accurate future projection of extreme drought events at the regional scale relies on adequate dynamical downscaling techniques that we can apply on large ensemble simulations to consider key physical processes determining climate extremes (Huang et al. 2018; Roberts et al. 2018). In addition, these two large ensemble experiments give only the future simulation under the RCP8.5 emission scenario, which is close to the current climate emission scenario, so it is important to study the uncertainty that stems from different emission scenarios.

It is inevitable that our results may exhibit differences with those derived from the traditional CMIP5 approach exploring the multimodel ensemble. This is especially expected at the subregional scale. For example, Wang et al. (2014) reported that the change of extreme drought events (SPEI $<-2.5)$ over southwest China will rise rapidly in the future, with the increase rate of PET exceeding that of precipitation.

Our analyses revealed that the increasing PET may dominate the risk rising of extreme drought events across China from a simple statistical perspective, which is consistent with previous works (Wang et al. 2014; Yao et al. 2020). However, more research is needed to verify the robustness of the results. The calculation of PET in our paper relies on a simple temperature-based equation. Contributions from factors other than PET, such as relative humidity and wind speed, may also play a role in the future changes of extreme drought at regional scale. In addition, it is necessary to investigate the relative contribution of precipitation deficits and temperature anomalies to the risk of extreme drought events by designing appropriate experiments, which could reveal the mechanisms for development of extreme drought events and shed light on the future drought risk at the regional scale.

The two large ensemble simulations that we analyzed have also been used in North America to study extreme meteorological droughts and hydrological droughts (Zhao et al. 2020). We extended their work to a new domain, China, a country acutely vulnerable to climate change. Due to the large geographic diversity, we furthermore divided the whole Chinese territory into subregions to better describe and understand the risk of extreme drought at local scale. CESM1-LE is believed to be more confident for risk assessment in north China with increasing frequency of extreme drought.

A comparison between our results with Zhao et al. (2020) revealed that there are disparities (but also similarities) among different regions of the world for future evolution of extreme droughts response to global warming. For example, SPEI at the 12-month scale used in our research is largely representative for the hydrological drought, comparable with Zhao et al. (2020) targeting hydrological droughts through the utilization of hydrological model driven by GCMs outputs. Most of our results in China are consistent with what is shown in Zhao et al. (2020) in North America. For example, future changes of drought frequency exhibit a quite uniform pattern of increase across those two domains. In addition, it is also interesting to note, for both regions, that temperature increase seems to play a more important role than precipitation does in driving the future evolution of extreme drought. 


\section{Conclusions}

The lack of enough statistical samples is often an obstacle to making reliable estimates of rare events of climate. Thanks to the large ensemble simulations released by the international climate modeling community, we have now enough statistical samples to use simple and direct sampling methodology to estimate probability of climate extremes. We used, in the present work, two large ensemble simulations from CanESM2LE and CESM1-LE to project the change in frequency of extreme droughts (events with a 100-yr return period) in China under different warming climates. Nevertheless, the coarse resolution of these GCMs still makes them subject to large biases in reproducing the climate at regional scale. A biascorrection method based on distribution quantile mapping was applied to daily precipitation and temperature remove biases. The bias-corrected data can well reproduce the observed characteristics of precipitation in the current climate with a huge reduction of wet biases in northern China and dry biases in southern China. The cold bias in the raw data is also largely reduced, especially in winter. The bias-removed data inspire more confidence in the projection of future extreme droughts.

An unbiased estimation was used to calculate the return period of extreme events and the future risks of extreme droughts were projected across China and its subregions under different warming levels. Our simple statistical scheme avoids making hypothetical assumptions on distribution of extreme events. Results show that the frequency of extreme droughts will increase with global warming, especially under higher warming levels. For China as a whole, the probability of a 100 -yr drought in the current climate increases by factors of 1.52 (1.44), 1.90 (2.02), 2.82 (3.83), and 4.43 (7.93) under $1.5^{\circ}$, $2^{\circ}, 3^{\circ}$, and $4^{\circ} \mathrm{C}$ warming levels in CanESM2-LE (CESM1$\mathrm{LE})$, respectively. The future risk changes at local scale exhibit large difference between two large ensemble simulations, with a large increase in north China for CESM1-LE but in south China for CanESM2-LE. The results from CESM1LE may inspire more confidence due to the model's finer spatial resolution.

The general increase of risk for a higher occurrence probability of extreme droughts is mainly due to the strong response of our drought index to PET changes as global warming progresses, with the PET effect of temperature surpassing that of precipitation. That is, the increase of PET plays a more and more important role in the increase of extreme droughts across China.

Acknowledgments. We thank the modeling groups at NCAR and CCCma for making the ensemble simulations available to us. This work is supported by the National Key Research and Development Program of China (Grants 2018YFC1507704, 2017YFA0603804, 2018YFC1507703), the National Natural Science Foundation of China (41905078), the Startup Foundation for Introducing Talent of NUIST, and the Youth Foundation of Jiangsu Meteorological Society (Grant KQ201915). The CESM1-LE was downloaded from the Large Ensemble Community Project (LENS) website (http://www.cesm.ucar.edu/projects/ community-projects/LENS/), the CanESM2-LE can be freely downloaded from http://data.ec.gc.ca/data/climate/. All three anonymous reviewers are much appreciated for their constructive comments and suggestions in improving this paper.

\section{REFERENCES}

Arora, V. K., and Coauthors, 2011: Carbon emission limits required to satisfy future representative concentration pathways of greenhouse gases. Geophys. Res. Lett., 38, L05805, https:// doi.org/10.1029/2010GL046270.

Barriopedro, D., C. M. Gouveia, R. M. Trigo, and L. Wang, 2012: The 2009/10 drought in China: Possible causes and impacts on vegetation. J. Hydrometeor., 13, 1251-1267, https://doi.org/ 10.1175/JHM-D-11-074.1.

Chen, H., and J. Sun, 2015: Changes in drought characteristics over China using the standardized precipitation evapotranspiration index. J. Climate, 28, 5430-5447, https://doi.org/10.1175/JCLID-14-00707.1.

Chen, J., F. P. Brissette, D. Chaumont, and M. Braun, 2013: Performance and uncertainty evaluation of empirical downscaling methods in quantifying the climate change impacts on hydrology over two North American river basins. J. Hydrol., 479, 200-214, https://doi.org/10.1016/j.jhydrol.2012.11.062.

,-- X. J. Zhang, H. Chen, S. Guo, and Y. Zhao, 2019: Bias correcting climate model multi-member ensembles to assess climate change impacts on hydrology. Climatic Change, 153, 361-377, https://doi.org/10.1007/s10584-019-02393-x.

Cook, B. I., Ault, T. R., Smerdon, J. E. 2015: Unprecedented 21st century drought risk in the American southwest and central plains. Sci. Adv., 1, e1400082, https://doi.org/10.1126/SCIADV. 1400082.

Cunnane, C., 1978: Unbiased plotting positions-A review. J. Hydrol., 37, 205-222, https://doi.org/10.1016/0022-1694(78)90017-3.

Dai, A. G., 2011: Drought under global warming: A review. Wiley Interdiscip. Rev.: Climate Change, 2, 45-65, https://doi.org/ 10.1002/WCC.81.

Deser, C., and Coauthors, 2020: Insights from Earth system model initial-condition large ensembles and future prospects. Nat. Climate Change, 10, 277-286, https://doi.org/10.1038/s41558020-0731-2.

Fischer, T., M. Gemmer, L. Liu, and B. D. Su, 2011: Temperature and precipitation trends and dryness/wetness pattern in the Zhujiang River Basin, South China, 1961-2007. Quat. Int., 244, 138-148, https://doi.org/10.1016/j.quaint.2010.08.010.

Folland, C., and C. Anderson, 2002: Estimating changing extremes using empirical ranking methods. J. Climate, 15, 2954-2960, https://doi.org/10.1175/1520-0442(2002)015<2954: ECEUER $>2.0 . \mathrm{CO} ; 2$.

Guo, L., Z. Jiang, D. Chen, H. Le Treut, and L. Li, 2020: Projected precipitation changes over China for global warming levels at $1.5^{\circ} \mathrm{C}$ and $2^{\circ} \mathrm{C}$ in an ensemble of regional climate simulations: Impact of bias correction methods. Climatic Change, 162, 623643, https://doi.org/10.1007/s10584-020-02841-z.

Huang, J., and Coauthors, 2018: Analysis of future drought characteristics in China using the regional climate model CCLM. Climate Dyn., 50, 507-525, https://doi.org/10.1007/s00382-017-3623-z.

Jeffrey, S., and Coauthors, 2013: Australia's CMIP5 submission using the CSIRO-Mk3.6 model. Aust. Meteor. Oceanogr. J., 63 (1), 1-13, https://doi.org/10.22499/2.6301.001.

Jiang, Z., W. Li, J. Xu, and L. Li, 2015: Extreme precipitation indices over China in CMIP5 models. Part I: Model evaluation. J. Climate, 28, 8603-8619, https://doi.org/10.1175/JCLI-D-150099.1. 
Kallis, G., 2008: Droughts. Annu. Rev. Environ. Resour., 33, 85-118, https://doi.org/10.1146/annurev.environ.33.081307.123117.

Kay, J. E., and Coauthors, 2015: The Community Earth System Model (CESM) large ensemble project: A community resource for studying climate change in the presence of internal climate variability. Bull. Amer. Meteor. Soc., 96, 1333-1349, https://doi.org/10.1175/BAMS-D-13-00255.1.

Kharin, V. V., F. W. Zwiers, X. Zhang, and M. Wehner, 2013: Changes in temperature and precipitation extremes in the CMIP5 ensemble. Climatic Change, 119, 345-357, https://doi.org/ 10.1007/s10584-013-0705-8.

Kirchmeier-Young, M. C., F. W. Zwiers, and N. P. Gillett, 2017: Attribution of extreme events in Arctic sea ice extent. J. Climate, 30, 553-571, https://doi.org/10.1175/JCLI-D-16-0412.1.

Lehner, F., C. Deser, and B. M. Sanderson, 2016: Future risk of record-breaking summer temperatures and its mitigation. Climatic Change, 146, 363-375, https://doi.org/10.1007/S10584016-1616-2.

Leng, G., Q. Tang, and S. Rayburg, 2015: Climate change impacts on meteorological, agricultural and hydrological droughts in China. Global Planet. Change, 126, 23-34, https://doi.org/10.1016/ j.gloplacha.2015.01.003.

Li, B., Z. Liang, Z. Yu, and K. Acharya, 2014: Evaluation of drought and wetness episodes in a cold region (Northeast China) since 1898 with different drought indices. Nat. Hazards, 71, 2063-2085, https://doi.org/10.1007/s11069-0130999-x.

- — - J. Zhang, and G. Wang, 2017: A revised drought index based on precipitation and pan evaporation. Int. J. Climatol., 37, 793-801, https://doi.org/10.1002/joc.4740.

Li, M., and Z. Ma, 2015: Soil moisture drought detection and multitemporal variability across China. Sci. China Earth Sci., 58, 1798-1813, https://doi.org/10.1007/s11430-015-5076-8.

Li, W., Z. Jiang, X. Zhang, L. Li, and Y. Sun, 2018: Additional risk in extreme precipitation in China from $1.5^{\circ} \mathrm{C}$ to $2.0^{\circ} \mathrm{C}$ global warming levels. Sci. Bull., 63, 228-234, https://doi.org/10.1016/ j.scib.2017.12.021.

Lu, E., Luo, Y., Zhang, R., Wu, Q., Liu, L. 2011: Regional atmospheric anomalies responsible for the 2009-2010 severe drought in China. J. Geophys. Res., 116, D21114, https://doi.org/10.1029/ 2011JD015706.

_, W. Cai, Z. Jiang, Q. Zhang, C. Zhang, R. W. Higgins, and M. S. Halpert, 2014: The day-to-day monitoring of the 2011 severe drought in China. Climate Dyn., 43 (1-2), 1-9, https:// doi.org/10.1007/s00382-013-1987-2.

Ma, S., T. Zhou, A. Dai, and Z. Han, 2015: Observed changes in the distributions of daily precipitation frequency and amount over China from 1960 to 2013. J. Climate, 28, 6960-6978, https:// doi.org/10.1175/JCLI-D-15-0011.1.

,$- \ldots$, O. Angélil, and H. Shiogama, 2017: Increased chances of drought in southeastern periphery of the Tibetan Plateau induced by anthropogenic warming. J. Climate, 30, 6543-6560, https://doi.org/10.1175/JCLI-D-16-0636.1.

Maher, N., and Coauthors, 2019: The Max Planck Institute Grand Ensemble: Enabling the exploration of climate system variability. J. Adv. Model. Earth Syst., 11, 2050-2069, https://doi.org/ 10.1029/2019MS001639.

Miao, L., S. Li, F. Zhang, T. Chen, Y. Shan, and Y. Zhang, 2020: Future drought in the dry lands of Asia under the 1.5 and $2.0^{\circ} \mathrm{C}$ warming scenarios. Earth's Future, 8, e2019EF001337, https:// doi.org/10.1029/2019EF001337.

Ou, T., D. Chen, H. W. Linderholm, and J. H. Jeong, 2013: Evaluation of global climate models in simulating extreme precipitation in China. Tellus, 65A, 19799, https://doi.org/ 10.3402/tellusa.v65i0.19799.

Qian, W. H., Lin, X. 2005: Regional trends in recent precipitation indices in China. Meteor. Atmos. Phys., 90, 193-207, https:// doi.org/10.1007/s00703-004-0101-z.

Qiu, S., W. Zhou, M. Y. T. Leung, and X. Li, 2017: Regional moisture budget associated with drought/flood events over China. Prog. Earth Planet. Sci., 4, 36, https://doi.org/10.1186/ s40645-017-0148-3.

Roberts, M. J., and Coauthors, 2018: The benefits of global high resolution for climate simulation process understanding and the enabling of stakeholder decisions at the regional scale. Bull. Amer. Meteor. Soc., 99, 2341-2359, https://doi.org/ 10.1175/BAMS-D-15-00320.1.

Rodgers, K. B., J. Lin, and T. L. Frölicher, 2015: Emergence of multiple ocean ecosystem drivers in a large ensemble suite with an Earth system model. Biogeosciences, 12, 3301-3320, https://doi.org/10.5194/bg-12-3301-2015.

Sheffield, J., E. F. Wood, and M. L. Roderick, 2012: Little change in global drought over the past 60 years. Nature, 491, 435-438, https://doi.org/10.1038/nature11575.

Shi, C., Z. H. Jiang, W. L. Chen, and L. Li, 2018: Changes in temperature extremes over China under $1.5^{\circ} \mathrm{C}$ and $2^{\circ} \mathrm{C}$ global warming targets. Adv. Climate Change Res., 9, 120-129, https://doi.org/10.1016/j.accre.2017.11.003.

Shi, J., L. Cui, and Z. Shen, 2020: Interannual variation and hazard analysis of meteorological disasters in east China. J. Risk Anal. Crisis Response, 9, 168-176, https://doi.org/ 10.2991/jracr.k.200117.004.

Sippel, S., D. Mitchell, M. T. Black, A. J. Dittus, L. J. Harrington, N. Schaller, and F. E. Otto, 2015: Combining large model ensembles with extreme value statistics to improve attribution statements of rare events. Wea. Climate Extremes, 9, 25-35, https://doi.org/10.1016/j.wace.2015.06.004.

Su, B., and Coauthors, 2018: Drought losses in China might double between the $1.5^{\circ} \mathrm{C}$ and $2.0^{\circ} \mathrm{C}$ warming. Proc. Natl. Acad. Sci. USA, 115, 10 600-10 605, https://doi.org/10.1073/PNAS.1802129115.

Sun, S. L., and Coauthors, 2019: Revisiting the evolution of the 20092011 meteorological drought over Southwest China. J. Hydrol., 568, 385-402, https://doi.org/10.1016/j.jhydrol.2018.10.071.

Sun, Y., X. Zhang, F. W. Zwiers, L. Song, H. Wan, T. Hu, H. Yin, and G. Ren, 2014: Rapid increase in the risk of extreme summer heat in Eastern China. Nat. Climate Change, 4, 10821085, https://doi.org/10.1038/nclimate2410.

— T. Tu, and X. B. Zhang, 2018: Substantial increase in heat wave risks in China in a future warmer world. Earth's Future, 6, 1528-1538, https://doi.org/10.1029/2018EF000963.

Tanaka, T., Y. Tachikawa, Y. Ichikawa, and K. Yorozu, 2018: Flood risk curve development with probabilistic rainfall modelling and large ensemble climate simulation data: A case study for the Yodo River basin. Hydrol. Res. Lett., 12, 28-33, https:// doi.org/10.3178/hrl.12.28.

Thornthwaite, C. W., 1948: An approach toward a rational classification of climate. Geogr. Rev., 38, 55-94, https://doi.org/ $10.2307 / 210739$.

Trenberth, K. E., A. Dai, G. V. D. Schrier, P. D. Jones, J. Barichivich, K. R. Briffa, and J. Sheffield, 2014: Global warming and changes in drought. Nat. Climate Change, 4, 1722, https://doi.org/10.1038/nclimate2067.

van der Wiel, K., N. Wanders, F. M. Selten, and M. F. P. Bierkens, 2019: Added value of large ensemble simulations for assessing extreme river discharge in a $2^{\circ} \mathrm{C}$ warmer world. Geophys. Res. Lett., 46, 2093-2102, https://doi.org/10.1029/2019GL081967. 
Vicente-Serrano, S. M., S. Beguería, and J. I. López-Moreno, 2010: A multiscalar drought index sensitive to global warming: The Standardized Precipitation Evapotranspiration Index. J. Climate, 23, 1696-1718, https://doi.org/10.1175/2009JCLI2909.1.

Wang, L., W. Chen, and W. Zhou, 2014: Assessment of future drought in southwest China based on CMIP5 multimodel projections. Adv. Atmos. Sci., 31, 1035-1050, https://doi.org/ 10.1007/s00376-014-3223-3.

Williams, A. P., and Coauthors, 2020: Large contribution from anthropogenic warming to an emerging North American megadrought. Science, 368, 314-318, https://doi.org/10.1126/ science.aaz9600.

World Meteorological Organization, 2019: WMO statement on the state of the global climate in 2019. WMO 1248, 44 pp., https:// library.wmo.int/index.php?lvl=notice_display\&id $=21700$.

Yang, J. H., Q. Zhang, J. S. Wang, J. L. Shang, and H. Y. Zhang, 2015: Spring persistent droughts anomaly characteristics of over the Southwest China in recent 60 years (in Chinese). Arid Land Geogr., 38, 215-222.

Yang, X., E. F. Wood, J. Sheffield, L. Ren, M. Zhang, and Y. Wang, 2018: Bias correction of historical and future simulations of precipitation and temperature for China from CMIP5 models. J. Hydrometeor., 19, 609-623, https://doi.org/10.1175/JHM-D-17-0180.1.

Yao, N., Y. Li, N. Li, D. Yang, and O. O. Ayantobo, 2018: Bias correction of precipitation data and its effects on aridity and drought assessment in China over 1961-2015. Sci. Total Environ., 639, 1015-1027, https://doi.org/10.1016/j.scitotenv. 2018.05.243.

— and Coauthors, 2020: Projections of drought characteristics in China based on a standardized precipitation and evapotranspiration index and multiple GCMs. Sci. Total Environ., 704, 135245, https://doi.org/10.1016/j.scitotenv.2019.135245.

Yin, H., and Y. Sun, 2018: Characteristics of extreme temperature and precipitation in China in 2017 based on ETCCDI indices.
Adv. Climate Change Res., 9, 218-226, https://doi.org/10.1016/ j.accre.2019.01.001.

Yu, M., Q. Li, M. J. Hayes, M. D. Svoboda, and R. R. Heim, 2014: Are droughts becoming more frequent or severe in China based on the standardized precipitation evapotranspiration index: 1951-2010? Int. J. Climatol., 34, 545-558, https://doi.org/ 10.1002/joc.3701.

Zhai, P., X. Zhang, H. Wan, and X. Pan, 2005: Trends in total precipitation and frequency of daily precipitation extremes over China. J. Climate, 18, 1096-1108, https://doi.org/10.1175/ JCLI-3318.1.

Zhang, L., and V. P. Singh, 2006: Bivariate flood frequency analysis using the copula method. J. Hydrol. Eng. 11, 150-164. https:// doi.org/10.1061/(ASCE)1084-0699(2006)11:2(150).

— J. F. Xiao, J. Li, K. Wang, L. P. Lei, and H. D. Guo, 2012: The 2010 spring drought reduced primary productivity in Southwestern China. Environ. Res. Lett., 7, 045706, https:// doi.org/10.1088/1748-9326/7/4/045706.

Zhang, Y., Q. You, C. Chen, and X. Li, 2017: Flash droughts in a typical humid and subtropical basin: A case study in the Gan River basin, China. J. Hydrol., 551, 162-176, https://doi.org/ 10.1016/j.jhydrol.2017.05.044.

Zhao, C., F. Brissette, J. Chen, and J. L. Martel, 2020: Frequency change of future extreme summer meteorological and hydrological droughts over North America. J. Hydrol., 584, 124316, https://doi.org/10.1016/j.jhydrol.2019.124316.

Zhao, T., and A. Dai, 2015: The magnitude and causes of global drought changes in the twenty-first century under a lowmoderate emissions scenario. J. Climate, 28, 4490-4512, https:// doi.org/10.1175/JCLI-D-14-00363.1.

_ and - 2017: Uncertainties in historical changes and future projections of drought. Part II: Model simulated historical and future drought changes. Climatic Change, 144, 535-548, https:// doi.org/10.1007/s10584-016-1742-x. 
